Cahiers $d u$ MONDE RUSSE

\section{Cahiers du monde russe}

Russie - Empire russe - Union soviétique et États indépendants

$44 / 4 \mid 2003$

Varia

\title{
B. Dolinin, B. Ivanov, B. Ostanin, D. Severjuhin, eds., Leningradskij samizdat, 1950-1980-e
}

\section{Vitali Petranovskii et Dmitri Gouzévitch}

\section{(2) OpenEdition}

\section{Journals}

Édition électronique

URL : https://journals.openedition.org/monderusse/4132

DOI : 10.4000/monderusse.4132

ISSN : $1777-5388$

Éditeur

Éditions de l'EHESS

\section{Édition imprimée}

Date de publication : 1 octobre 2003

Pagination : 775-777

ISBN : 2-7132-1833-0

ISSN : $1252-6576$

Référence électronique

Vitali Petranovskii et Dmitri Gouzévitch, « B. Dolinin, B. Ivanov, B. Ostanin, D. Severjuhin, eds.,

Leningradskii samizdat, 1950-1980-e », Cahiers du monde russe [En ligne], 44/4 | 2003, mis en ligne le

19 juin 2009, consulté le 03 septembre 2022. URL : http://journals.openedition.org/monderusse/4132 ; DOI : https://doi.org/10.4000/monderusse.4132

Ce document a été généré automatiquement le 3 septembre 2022.

Tous droits réservés 


\title{
B. Dolinin, B. Ivanov, B. Ostanin, D. Severjuhin, eds., Leningradskij samizdat, 1950-1980-e
}

\author{
Vitali Petranovskii et Dmitri Gouzévitch
}

\section{RÉFÉRENCE}

B. DOLININ, B. IVANOV, B. OSTANIN, D. SEVERJUHIN, eds., Leningradskij samizdat, 1950-1980-e. Literaturnaja enciklopedija. Moscou, Novoe literaturnoe obozrenie, 2003, $624 \mathrm{p}$.

1 Le samizdat - phénomène par nature non gutenbergien - est dorénavant perpétué dans la " galaxie de Gutenberg ». L'encyclopédie du samizdatlittéraire vient de paraître (d'autres formes de samizdat - politique, religieux, musical - étant laissées en marge de cette édition).

2 Critiquer cet ouvrage serait chose facile mais insensée, voire immorale, car, malgré des insuffisances évidentes, les éditeurs sont allés au-delà de ce qui était possible. Pour cette raison, les commentaires qui suivent visent surtout à compléter le travail réalisé.

3 Il s'agit, à l'origine, de textes manuscrits et dactylographiés, « publiés » en nombre infime (d'un à quelques dizaines d'exemplaires) et multipliés, dans le meilleur des cas, à l'aide de diverses techniques de reproduction (photographie, photocopie, stencil, bleu). La collecte des matériaux s'est effectuée essentiellement par le biais d'entretiens avec d'anciens acteurs du samizdat. Il s'agit donc d'une mémoire collective fixée sur le papier. Les auteurs indiquent que "la taille d'une notice ne reflète que le volume des renseignements accessibles». Ce volume influence à son tour le nombre de notices, ajouterons-nous. «L'éclatement des groupes littéraires autonomes, l'absence de témoignages écrits concernant leur activité, le caractère très approximatif des souvenirs oraux de leurs membres peuvent expliquer l'indigence des informations collectées », mais les auteurs(et 
les lecteurs !) espèrent que « l'occasion se présentera de combler ces lacunes dans l'avenir ». Cependant, l'essentiel est fait - les premiers résultats des recherches ont été rendus publics.

4 Le mot "samizdat " que l'URSS a offert au monde entier, de même que "spoutnik » et "perestroïka», est absent des dictionnaires soviétiques. Le dictionnaire américain Webster ${ }^{1}$ le définit ainsi : "Samizdat [Russ]. (1970) The system in the USSR by which government-suppressed literature is clandestinely printed and distributed; also: such literature. » L'ouvrage analysé ici, quant à lui, ne donne pas de définition. Les auteurs se contentent de décrire le samizdat comme "parole écrite soustraite au contrôle du pouvoir ", "mouvement culturel indépendant ", " collecte et conservation de textes littéraires destinés à une publication non officielle». Ils amalgament par ailleurs quelques phénomènes très proches dont le samizdat ne constitue qu'une partie. Ainsi, l'attribution du prix Andrej Belyj n'est pas du samizdat en soi, bien qu'il soit destiné à récompenser des éditions du sam-izdat. Par contre, la publication du rapport concernant son attribution devient une expression du samizdat. Quant au prix lui-même, il fait partie des manifestations du mouvement du samizdat en tant qu'institution sociale. Autrement dit, le mot samizdat désigne à la fois une institution sociale et sa production.

Parmi les phénomènes qui s'y rattachent, on peut citer la chanson d'auteur, la poésie orale, la production musicale et artistique underground. Certains relèvent de deux domaines simultanément (par exemple les textes publiés des chansons d'auteur).

Le lecteur peut être surpris par l'effet que peut produire une certaine héroïsation des personnages. C'est un élément qui n'est pas le fait des éditeurs, mais auquel, pour des raisons éthiques, il est aujourd'hui difficile de remédier. Le KGB surveillait la plupart des acteurs concernés. La panoplie des " contacts » était variée : entretiens " préventifs", menaces, perquisitions, interrogations, racolage, arrestation, exil, réclusion, etc. Face à ces éventualités, les gens réagissaient différemment et, à la lecture de l'encyclopédie, il arrive qu'on se souvienne que l'un des ex-prisonniers avait "donné » l'autre, qu'un troisième était délateur... Mais nous ne sommes pas en droit de les juger, ni encore moins de diffuser les rumeurs qui circulent.

7 Le livre est plaisant, édité avec amour et bien illustré. Un seul reproche : l'absence d'index général des noms.

\section{Le samizdat est mort...}

8 Les éditeurs ont limité le cadre chronologique de leur étude, car aujourd'hui « la notion même de "culture non officielle" a perdu son sens d'autrefois. Le samizdat traditionnel n'a plus le monopole de la parole libre, il a cédé la place à l'impression légale [...]. Les barrières économiques se sont substituées à celles de la censure. L'époque du samizdat a été reléguée dans le domaine de l'histoire, nous laissant en héritage une expérience unique de la parole libre qui résonnait en dépit du mutisme imposé par l'idéologie officielle» (p. 51). Mais les barrières économiques se sont-elles réellement substituées à celles de la censure?

Car, désormais, le samizdat est ressuscité. Il a pour fonction de diffuser les œuvres non accessibles pour cause de censure (autrefois) ou pour cause économique (aujourd'hui). Un nouveau medium, Internet, permet de remplir cette fonction rapidement et efficacement. Tout usager peut avoir accès à la bibliothèque Maksim Moškov (http:// www.lib.ru/) ou à la revue littéraire Samizdat (http://zhurnal.lib.ru/). Extrait de l'interview de Maksim Moškov au journal Izvestija (http://www.izvestia.ru/tech/ 
article33286) : «Dans la bibliothèque figure une section destinée à l'édition autonome de textes. On y trouve déjà 7500 auteurs ». Et encore : « Pour ce qui est des droits d'auteur et des dommages que peut causer aux auteurs ma bibliothèque, voilà quelle est la situation : aujourd'hui, un Russe dépense 300 roubles (10 dollars) par an pour acheter des livres. Les éditions reversent à l'auteur $9 \%$ du prix de gros du livre, de sorte que sur les 10 dollars payés par le citoyen, l'auteur touche 30 cents imposables. Pour vivre du produit de la vente de ses livres, il faudrait avoir un tirage annuel de 100000 exemplaires. Alors que les écrivains souhaitent être lus, recevoir des échos des lecteurs. Il en ressort que la publication sur Internet contribue à la notoriété et n'occasionne pas de perte matérielle. Durant toute l'existence du site lib.ru, une vingtaine d'auteurs seulement ont demandé qu'on enlève leurs textes. Ce qui a été fait ».

Internet ne peut-il être considéré comme une forme de « samizdat mondial » permettant à chacun de participer à la culture du monde entier en contournant toute forme de censure idéologique ou économique ? Le samizdat de l'époque soviétique était une forme de "monopole de la parole libre ", son essence même consistant en une lutte contre un monopole sur la culture. Pour toutes ces raisons, la compréhension de «l'expérience unique de la parole libre qui résonnait en dépit du mutisme imposé par l'idéologie officielle »n'a rien perdu de son acuité. Cette encyclopédie paraît au bon moment.

\section{NOTES}

1. Webster's ninth new college dictionary, Springfield, MA, 1985, p. 1040. 